Check for updates

Cite this: RSC Adv., 2017, 7, 55668

Received 10th October 2017

Accepted 4th December 2017

DOI: $10.1039 / c 7 r a 11159 b$

rsc.li/rsc-advances

\section{A novel fluorescence polarization assay for copper ions based on DNA-templated click chemistry and amplification of nanoparticles $\uparrow$}

\begin{abstract}
Suqi Liao, ${ }^{\mathrm{b}}$ Jingjin Zhao, (D) *ab Yingfeng Qin ${ }^{\mathrm{a}}$ and Shulin Zhao (D) ${ }^{\mathrm{b}}$
In this work, we developed a novel fluorescence polarization (FP) method for the sensitive detection of $\mathrm{Cu}^{2+}$ based on the chemical ligation of DNA by click chemistry and silica nanoparticles-assisted FP enhancement. A double-stranded DNA hybrid (P1P2) is used as an "end-of-helix" template with an alkyne group and an azide group at the end of two DNA strands, respectively. $\mathrm{Cu}^{2+}$ can be reduced to $\mathrm{Cu}^{+}$by sodium ascorbate, and trigger the chemical ligation P1P2 through the $\mathrm{Cu}^{+}$-catalyzed azide-alkyne cycloaddition. A biotin-labeled P3 which can hybridize with P1 is introduced to displace the FAM-contained P2 from P1P2 duplex. Since P1 and P2 are linked after the $\mathrm{Cu}^{2+}$-triggered click chemistry, a P1P2P3 complex is formed which can be captured on the silica nanoparticle surface through the biotin-streptavidin interaction, thus achieving a high FP signal. In the absence of $\mathrm{Cu}^{2+}$, there is no ligation between P1 and $P 2$. The released P2 is free and cannot be immobilized on the nanoparticle surface, resulting in a low FP. The specificity of click chemistry provides a high selectivity, and the nanoparticle-assisted FP enhancement provides a high sensitivity with a detection limit of $0.0178 \mu \mathrm{M}$. This method also displays good assay performance in real water samples, which may be further used for environmental monitoring.
\end{abstract}

\section{Introduction}

Copper is an essential biological trace element, and one of the most familiar metals in daily life as it is a vital component of proteins and enzymes in the body. ${ }^{1}$ The lack of copper in the human body may cause copper deficiency diseases, including anaemia, and certain heart, circulatory and intestinal problems. ${ }^{2}$ However, copper is also harmful to the human body at elevated concentrations, leading to cirrhosis of the liver, diarrhea, vomiting, movement disorders, and perception of neurological disorders. ${ }^{3}$ Several methods have been developed to detect copper ions, including atomic absorption spectrometry, ${ }^{4}$ coupled plasma mass spectrometry, ${ }^{5}$ electrochemical, ${ }^{6}$ colorimetric, ${ }^{7}$ fluorescent methods. ${ }^{8}$ Although these methods are very sensitive, they require expensive equipment, or need relatively complicated test process, or are interference by other metal ions easily. In this regard, the establishment of convenient methods to detect trace copper with high sensitivity and selectivity has become more and more significant in biological and environmental analysis.

\footnotetext{
${ }^{a}$ Key Laboratory of Ecology of Rare and Endangered Species and Environmental Protection of Ministry Education, Guangxi Normal University, Guilin 541004, PR China. E-mail: jzhao12@163.com; Fax: +86-773-583-2294; Tel: +86-0773-212-0226

${ }^{b}$ State Key Laboratory for the Chemistry and Molecular Engineering of Medicinal Resources, Guangxi Normal University, Guilin 541004, China

$\dagger$ Electronic supplementary information (ESI) available: Supplementary figures. See DOI: $10.1039 / \mathrm{c} 7 \mathrm{ra11159b}$
}

$\mathrm{Cu}^{+}$-catalyzed azide-alkyne cycloaddition (CuAAC) reaction is a typical example of "Click Chemistry". It has the advantages of mild reaction conditions, high reaction rate, high yield, and facile purification with almost no byproducts. The reaction proceeds by the $\mathrm{Cu}^{+}$-catalyzed cycloaddition of a terminal alkyne and azide, forming a stable triazole compound. It is highly specific, as $\mathrm{Cu}^{+}$only catalyzes the reaction at terminal alkynes. ${ }^{9}$ As these unique characteristics, CuAAC reaction is commonly applied in many fields, including drug research and development, ${ }^{\mathbf{1 0}}$ polymer synthesis, ${ }^{\mathbf{1 1}}$ and functionalization of biological macromolecules. ${ }^{12}$ Recently, CuAAC has also been used as a linking tool for DNA chemical ligation and introduced for the detection of copper ions. For example, Mirkin's group reported a colorimetric $\mathrm{Cu}^{2+}$ sensor based on click chemistrytriggered ligation of DNA-modified gold nanoparticles. ${ }^{13}$ Nie's group used DNA-templated click reaction to mediate intramolecular G-quadruplex structure formation for developing a fluorescence $\mathrm{Cu}^{2+}$ detection method. ${ }^{14}$

Here, we presented the first example of using fluorescence polarization (FP) technique to detect $\mathrm{Cu}^{2+}$ through CuAAC strategy. FP is a simple quantitative method related to the molecular mass and volume of fluorescent molecules. ${ }^{15}$ The degree of FP exhibited by a molecule is inversely proportional to its rotational speed. Thus, larger molecules with slower rotation present stronger FP, whereas smaller molecules with faster rotation present weaker FP. When performed in homogeneous solution, the FP technique has the advantages of simple operation, high sensitivity, and good reproducibility, and has thus 
received much attention in life science. ${ }^{\mathbf{1 6}}$ In recent years, to further improve the sensitivity of FP, researchers have developed signal amplification methods, such as the use of silica nanoparticles, ${ }^{17}$ carbon nanotubes, ${ }^{18}$ proteins, ${ }^{19}$ and gold nanoparticles ${ }^{20}$ to enhance the FP signal. In this work, we used CuAAC reaction to chemically ligase DNA chains and introduced streptavidin-modified silica nanoparticles $\left(\mathrm{SA}^{\left.-\mathrm{SiO}_{2}\right)}\right.$ to enhance FP, thus developing a novel signal-amplification method for the detection of $\mathrm{Cu}^{2+}$. The specific $\mathrm{CuAAC}$ reaction provides a good selectivity, and the FP amplification by silica nanoparticles gives a high sensitivity. This method also exhibits an acceptable assay performance in river water samples, which may be further used for environmental monitoring.

\section{Experimental}

\subsection{Reagents and instruments}

Streptavidin-modified silica nanoparticles $\left(\mathrm{SA}^{\left.-\mathrm{SiO}_{2}\right)}\right.$ were purchased from Bangs Laboratories Inc., USA. Tris-(hydroxypropyltriazolylmethyl) amine (THPTA) was obtained from Sigma, USA. Sodium ascorbate (NaVC) was bought from Shanghai Sangon Biotech. All other reagents used in the experiments were made in China and of analytical grade. Ultrapure water with an electrical resistance of $18.2 \mathrm{M} \Omega \mathrm{cm}$ was used throughout this study. The DNA fragments used in this study were synthesized by Shanghai Sangon Biotech Co. Ltd. The sequences are shown below:

\section{P1: $\mathrm{CH} \equiv \mathrm{CH}-\mathrm{GCGTCGCCAGGTCC}$ \\ P2: FAM-GGCGACGC-N 3 \\ P3: GGACCTGGCGACGCAGCGTCG-Biotin}

A DNA stock solution was made by centrifuging DNA at $12000 \mathrm{rpm}$ for $1 \mathrm{~min}$ and dissolving in ultrapure water to a concentration of $20 \mu \mathrm{M}$. The solution was then allowed to stand at $4{ }^{\circ} \mathrm{C}$ for $24 \mathrm{~h}$ and stored at $-20{ }^{\circ} \mathrm{C}$ prior to use. $10 \times$ Tris-HCl buffer ( $\mathrm{pH}$ 7.0) contained $0.2 \mathrm{M}$ Tris- $\mathrm{HCl}$ and $1 \mathrm{M}$ $\mathrm{NaCl}$ was used in this work.

\subsection{Fluorescence polarization detection of $\mathrm{Cu}^{2+}$}

$\mathrm{P} 1$ and $\mathrm{P} 2$ with equal concentration were mixed in $1 \times$ Tris- $\mathrm{HCl}$ buffer (0.02 M Tris- $\mathrm{HCl}$ and $0.1 \mathrm{M} \mathrm{NaCl}, \mathrm{pH}$ 7.0). The mixture was then heated at $95{ }^{\circ} \mathrm{C}$ for $5 \mathrm{~min}$, followed by cooling to room temperature to obtain the duplex $\mathrm{P} 1 \mathrm{P} 2$ probe. After that, $11.1 \mu \mathrm{L}$ of $\mathrm{H}_{2} \mathrm{O}, 1.9 \mu \mathrm{L}$ of $10 \times$ Tris-HCl buffer, $1.0 \mu \mathrm{L}$ of $1.0 \mu \mathrm{M}$ P1P2, 2.0 $\mu \mathrm{L}$ of $10 \mathrm{mM}$ THPTA, $2.0 \mu \mathrm{L}$ of $5.0 \mathrm{mM} \mathrm{NaVC}$, and $2.0 \mu \mathrm{L}$ of a $\mathrm{CuSO}_{4}$ solution with different concentration were mixed well. After reacting at room temperature for $120 \mathrm{~min}, 16 \mu \mathrm{L}$ of $\mathrm{H}_{2} \mathrm{O}$, $2.0 \mu \mathrm{L}$ of $10 \times$ Tris-HCl buffer, and $2.0 \mu \mathrm{L}$ of $2.0 \mu \mathrm{M}$ P3 were added and reacted for $60 \mathrm{~min}$ at $37^{\circ} \mathrm{C}$. Then, $8.0 \mu \mathrm{L}$ of $\mathrm{H}_{2} \mathrm{O}, 1.0$ $\mu \mathrm{L}$ of $10 \times$ Tris-HCl buffer, and $1.0 \mu \mathrm{L}$ of $0.50 \mu \mathrm{g} \mu \mathrm{L}^{-1} \mathrm{SA}_{-\mathrm{SiO}_{2}}$ were added to the reaction mixture, which was mixed well and allowed to react at $37{ }^{\circ} \mathrm{C}$ for $30 \mathrm{~min}$. After that, $25 \mu \mathrm{L}$ obtained solution was added into $75 \mu \mathrm{L}$ of $1 \times$ Tris- $\mathrm{HCl}$ buffer to give a $100 \mu \mathrm{L}$ of final solution for FP analysis. All FP measurements were performed using a Cary Eclipse fluorescence spectrophotometer (Agilent Technologies, USA) at an excitation wavelength of $485 \mathrm{~nm}$ with a slit-with of $10 \mathrm{~nm}$ for excitation and emission.
The FP signal was recorded at an emission wavelength of $520 \mathrm{~nm}$. Each sample was measured three times independently. The change of FP signals between the presence and absence of $\mathrm{Cu}^{2+}$ was used to evaluate the assay performance.

\subsection{Gel electrophoresis}

Agarose gel electrophoresis was used to confirm the chemical linkage of the P1 and P2 and its hybridization with P3. The samples were prepared as follows: $6.6 \mu \mathrm{L}$ of $\mathrm{H}_{2} \mathrm{O}, 1.4 \mu \mathrm{L}$ of $10 \times$ Tris-HCl buffer, $6.0 \mu \mathrm{L}$ of $10 \mu \mathrm{M}$ P1P2, $2.0 \mu \mathrm{L}$ of $10 \mathrm{mM}$ THPTA, $2.0 \mu \mathrm{L}$ of $5.0 \mathrm{mM} \mathrm{NaVC}$, and $2.0 \mu \mathrm{L}$ of $0.20 \mathrm{mM} \mathrm{CuSO}_{4}$ were thoroughly mixed at room temperature and allowed react for $120 \mathrm{~min}$. Then, $13.0 \mu \mathrm{L}$ of $\mathrm{H}_{2} \mathrm{O}, 2.0 \mu \mathrm{L}$ of $10 \times$ Tris- $\mathrm{HCl}$ buffer, and $3.0 \mu \mathrm{L}$ of $20 \mu \mathrm{M}$ P3 were added and allowed to react for $60 \mathrm{~min}$ at $37{ }^{\circ} \mathrm{C}$. Agarose gel electrophoresis was performed using a $4 \%$ agarose gel in $1 \times$ TBE buffer $9.0 \mathrm{mM}$ Tris, $9.0 \mathrm{mM}$ boric acid, and 0.2 mM EDTA, pH 7.9. $20 \mu \mathrm{L}$ of sample solution was added to each well, and the experiment was run under a constant voltage of $90 \mathrm{~V}$ for $90 \mathrm{~min}$. The results were imaged with an Omega 16ic gel imaging system and analyzed.

\section{Results and discussion}

\subsection{Design principle}

The principle of the proposed FP signal amplification strategy is outlined in Scheme 1 . The $5^{\prime}$ end of P1 was modified with an alkyne group, while the P2 was labelled with a fluorophore (FAM) at the $5^{\prime}$ end and an azide group at its $3^{\prime}$ end. P3 was modified with a biotin on the $3^{\prime}$ end, which is entirely complementary to $\mathrm{P} 1$ and also has 6 complementary base pairs to P2. A double-stranded DNA (dsDNA) hybrid (P1P2) is used as "end-of-helix" template bearing an alkyne group and an azide group at the end of two DNA strands, respectively. In the presence of $\mathrm{Cu}^{2+}, \mathrm{Cu}^{2+}$ is reduced to $\mathrm{Cu}^{+}$by sodium ascorbate (NaVC), and triggers the chemical ligation of P1 and P2 through

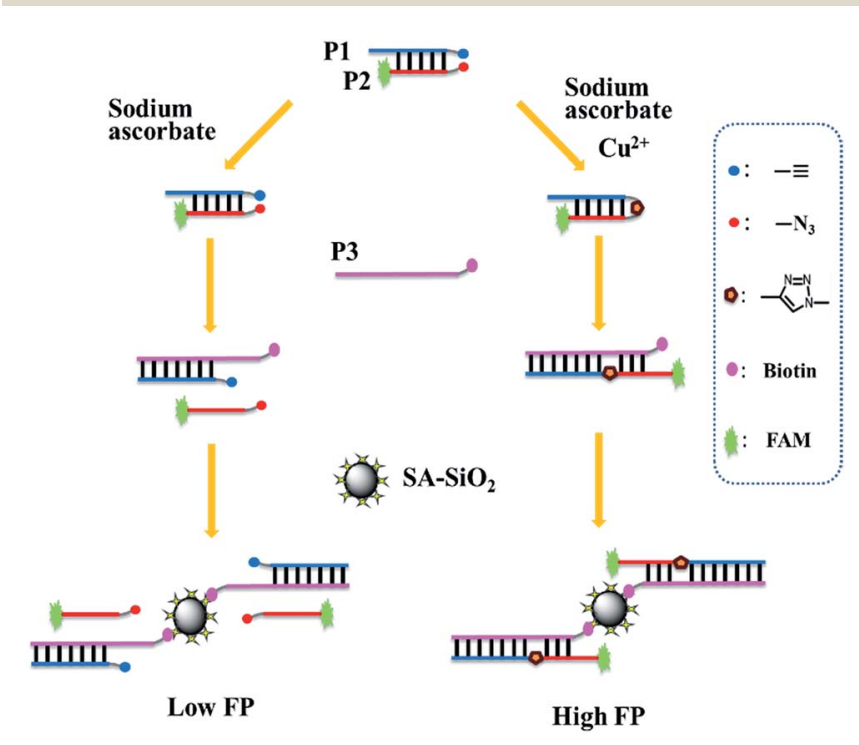

Scheme 1 Schematic illustration of the amplified FP assay for $\mathrm{Cu}^{2+}$ based on DNA-templated click chemistry and $\mathrm{SA}_{-} \mathrm{SiO}_{2}$. 
the $\mathrm{Cu}^{+}$-catalyzed azide-alkyne cycloaddition under the assistance of ligand Tris (hydroxy-propyltriazolyl methyl) amine (THPTA). The biotin-labelled P3 then hybridizes with P1 and displaces the P2. As P1 and P2 are linked, P2 is drawn closer to P3 and hybridizes with it to form a P1P2P3 complex. After the addition of $\mathrm{SA}_{-} \mathrm{SiO}_{2}$, the FAM-contained P1P2P3 complex binds to the surface of the nanoparticles through the specific bonding between biotin and streptavidin, forming P1P2P3/SA-SiO nanocomplex. Due to the larger molecular volume and mass of the formed nanocomplex, a stronger FP signal was therefore obtained. In the absence of $\mathrm{Cu}^{2+}$, the azide-alkyne cycloaddition does not proceed and no linking will occur between the ends of P1 and P2. When P3 and P1 hybridized, P2 is displaced. Because $\mathrm{P} 2$ and $\mathrm{P} 3$ are less complementary which brings a lower DNA melting temperature, P2 cannot hybridize with P3. Consequently, the addition of $\mathrm{SA}^{-\mathrm{SiO}_{2}}$ only leads to the formation of a P1P3/SA-SiO 2 nanocomplex. The FAM-labelled free P2 will give a weaker FP signal. Therefore, quantitative analysis of $\mathrm{Cu}^{2+}$ can be performed according to the change in FP signal.

\subsection{Feasibility study}

To verify the feasibility of the method concept, we first investigated the FP signal under different conditions. The change of FP signals $(\Delta \mathrm{FP})$ between the presence and absence of $\mathrm{Cu}^{2+}$ was used to evaluate the assay performance. As shown in Fig. 1, in the absence of P3, $\triangle \mathrm{FP}$ value is negligible. This is because that the FAM-labelled P2 can't combine to $\mathrm{SA}_{-} \mathrm{SiO}_{2}$ without the help of $\mathrm{P} 3$ even though the chemical ligation has taken place. At the same time, if the system contains no $\mathrm{SA}_{-} \mathrm{SiO}_{2}$ but with $\mathrm{P} 3$, only a small $\Delta \mathrm{FP}$ is observed. This is because the formed P1P2P3 complex has insufficient molecular volume/mass to significantly enhance FP signal. As expected, $\Delta \mathrm{FP}$ value is increased remarkably in the presence of both $\mathrm{P} 3$ and $\mathrm{SA}_{-} \mathrm{SiO}_{2}$. This is because the formation of P1P2P3 after $\mathrm{Cu}^{2+}$-triggered cycloaddition, which can be captured by $\mathrm{SA}^{-\mathrm{SiO}_{2}}$ to give a larger

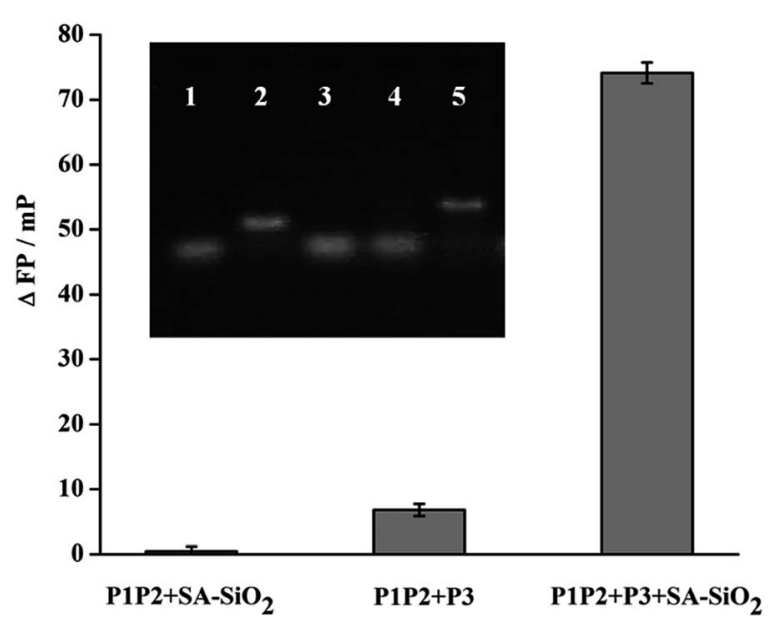

Fig. 1 The $\triangle \mathrm{FP}$ value at different conditions. Inset is the agarose gel electrophoresis images under the different conditions. Lane 1: P2; lane 2: P1P2; lane 3: P1P2 + P3; lane 4: P1P2 + P3 + NaVC + THPTA; lane 5: $\mathrm{P} 1 \mathrm{P} 2+\mathrm{P} 3+\mathrm{NaVC}+\mathrm{THPTA}+\mathrm{Cu}^{2+}$.
$\mathrm{P} 1 \mathrm{P} 2 \mathrm{P} 3 / \mathrm{SA}^{-\mathrm{SiO}_{2}}$ nanocomplex, greatly enhancing the FP signal. The above results show that this design principle is feasible and can be used for the quantitative detection of $\mathrm{Cu}^{2+}$.

The viability of proposed strategy was further investigated by gel electrophoresis. The results are shown in the inset of Fig. 1. P2 was labelled with a FAM fluorophore, which was used as an indicator here to show the position of P2-contanined DNA in the gel, thus providing the hybridization state information indirectly. Lane 1 and lane 2 are P2 and P1P2, respectively. When P3 is mixed with P1P2, only a band (lane 3) at the same position as that of P2 but not of P1P2 is observed. This indicates that the strand displacement took place through the hybridization of P3 and P1, and $\mathrm{P} 2$ was released from $\mathrm{P} 1 \mathrm{P} 2$. Lane 4 is the mixture of $\mathrm{P} 1 \mathrm{P} 2, \mathrm{P} 3$, $\mathrm{NaVC}$ and THPTA but without $\mathrm{Cu}^{2+}$. In this condition, no ligation was occurred and P2 could also be displaced by P3. Thus, in lane 4, it only exhibits a band at the similar position to $\mathrm{P} 2$ and the band of P1P2 disappeared. With the introduction of $\mathrm{Cu}^{2+}$, a new band with more slower mobility is obtained (lane 5). This result imply that the $\mathrm{P} 2$ was linked to the $\mathrm{P} 1$ through $\mathrm{Cu}^{+}$-catalyzed azide-alkyne cycloaddition, and then formed P1P2P3 complex. So, a band that moves slowly can be observed. The above gel electrophoresis results indicate that the formation of $\mathrm{P} 1 \mathrm{P} 2 \mathrm{P} 3$ relied on the presence of $\mathrm{Cu}^{2+}$, further verifying the present design principle.

\subsection{Assay performance}

To achieve a good assay performance, we optimized the conditions including the temperature, incubation time, and the solution $\mathrm{pH}$ of the click chemistry reaction, and the concentrations of used NaVC and $\mathrm{SA}-\mathrm{SiO}_{2}$. The experimental results show a largest $\triangle \mathrm{FP}$ value when the click chemistry was performed using $5 \mathrm{mM} \mathrm{NaVC}$ to reduce $\mathrm{Cu}^{2+}$ at $25^{\circ} \mathrm{C}$ for $120 \mathrm{~min}$ under a solution $\mathrm{pH}$ of 7.0 (Fig. $\mathrm{S} 1$, ESI $\dagger$ ). In addition, $\Delta \mathrm{FP}$ increased with increasing $\mathrm{SA}_{-} \mathrm{SiO}_{2}$ concentration and then decreased when the concentration was larger than $0.5 \mu \mathrm{g} \mu \mathrm{L}^{-1}$ (Fig. S2, ESI $\dagger$ ). Thus, this value was selected as the optimal SA$\mathrm{SiO}_{2}$ concentration for the following experiments.

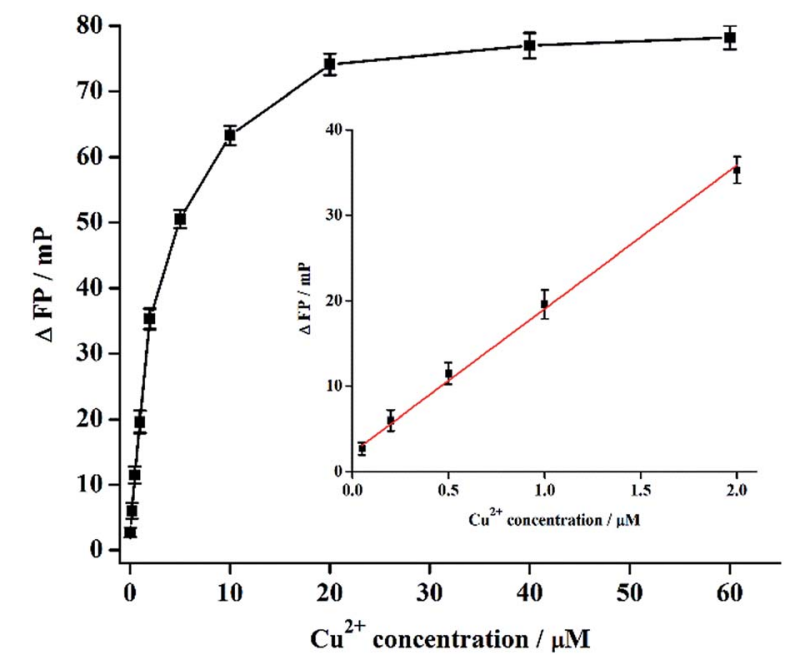

Fig. 2 Relationship between $\mathrm{Cu}^{2+}$ concentration and $\Delta \mathrm{FP}$. Inset shows the linear region of the curve. 


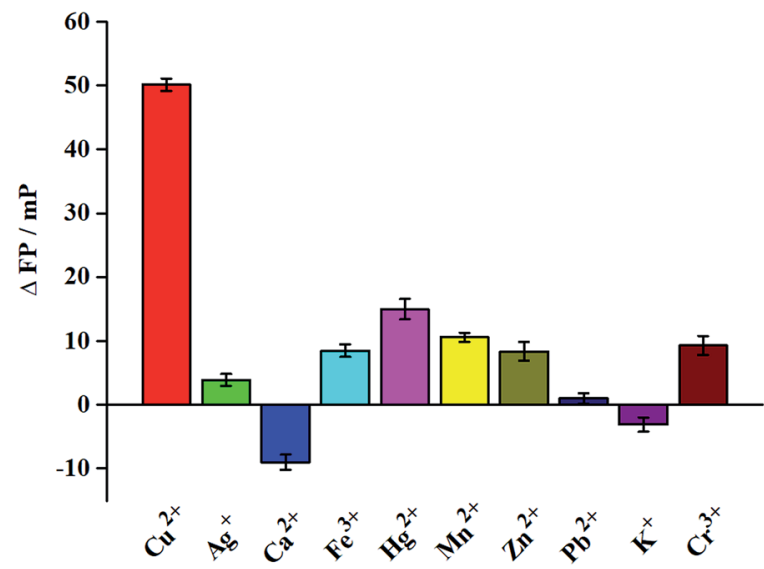

Fig. 3 Specificity of the proposed FP assay for $\mathrm{Cu}^{2+}$ detection. The concentration of $\mathrm{Cu}^{2+}$ is $5 \mu \mathrm{M}$, and all other metal ions are $20 \mu \mathrm{M}$.

Under the optimized experimental conditions, a series of $\mathrm{Cu}^{2+}$ solutions with different concentrations was analyzed, and the results are shown in Fig. 2. $\Delta \mathrm{FP}$ increases with increasing $\mathrm{Cu}^{2+}$ concentration from 0.050 to $20 \mu \mathrm{M}$, and reaches a plateau when the $\mathrm{Cu}^{2+}$ concentration is larger than $20 \mu \mathrm{M}$. $\Delta \mathrm{FP}$ shows a good linear relationship in the $\mathrm{Cu}^{2+}$ concentration rang of $0.050-2.0 \mu \mathrm{M}$ (inset of Fig. 2). The linear equation is $\Delta \mathrm{FP}=$ $16.81 C+2.25\left(C\right.$ is $\mathrm{Cu}^{2+}$ concentration $)$ with a correlation coefficient of 0.9960 . The detection limit (DL) is about 0.0178 $\mu \mathrm{M}(\mathrm{S} / \mathrm{N}=3)$. The assay performance of this method was also compared with other CuAAC-based $\mathrm{Cu}^{2+}$ determination methods (Table S1, ESI $\dagger$ ). Comparison results indicate that the proposed FP assay here can be used for sensitive detection of $\mathrm{Cu}^{2+}$ except a slightly longer assay time. The DL here is much lower than that of previously reported colorimetric method based on CuAAC-triggered aggregation of DNA-modified gold nanoparticles $(20 \mu \mathrm{M})^{\mathbf{1 3}}$ and colorimetric method coupled CuAAC-ligated DNA with unmodified gold nanoparticle (250 $\mathrm{nM}),{ }^{21}$ and is comparable to that of methods using DNAtemplated CuAAC to mediate G-quadruplex structure formation (65 nM for fluorescence detection, and $5.9 \mathrm{nM}$ for colorimetric method). ${ }^{\mathbf{1 4 2 2}}$ Though the assay time of our method is slightly longer than that of G-quadruplex ${ }^{\mathbf{1 4 , 2 2}}$ and unmodified gold nanoparticle ${ }^{21}$ based assays, it is much shorter than other methods, like fluorescence assay using CuAAC-triggered aggregation-induced emission of tetraphenylethene derivative $^{23}$ and commercial glucometer-based assay. ${ }^{24}$

To investigate the selectivity of the method, we utilized other environmentally related heavy metal ions, such as $\mathrm{Ag}^{+}, \mathrm{Ca}^{2+}$, $\mathrm{Fe}^{3+}, \mathrm{Hg}^{2+}, \mathrm{Mn}^{2+}, \mathrm{Zn}^{2+}, \mathrm{Pb}^{2+}, \mathrm{K}^{+}$, and $\mathrm{Cr}^{3+}$. As can be seen from the results in Fig. 3, only $\mathrm{Cu}^{2+}$ induce a significant change of FP signal, while the other metal ions have lesser effects even the concentration of interference metal ion $(20 \mu \mathrm{M})$ was larger than that of $\mathrm{Cu}^{2+}(5 \mu \mathrm{M})$. The results show that our method has high selectivity for the detection of $\mathrm{Cu}^{2+}$.

To study the applicability of this method, river water samples (Taohuajiang River, Guilin) spiked with different concentrations of $\mathrm{Cu}^{2+}$ were tested. The water samples were collected and pre-treated by centrifugation and filtration. ${ }^{8 b} \mathrm{Cu}^{2+}$ with different
Table 1 Recovery test for $\mathrm{Cu}^{2+}$ in river water samples

\begin{tabular}{lllll}
\hline Samples & $\begin{array}{l}\text { Added } \\
(\mu \mathrm{M})\end{array}$ & $\begin{array}{l}\text { Found } \\
(\mu \mathrm{M})\end{array}$ & $\begin{array}{l}\text { Recovery } \\
(\%)\end{array}$ & $\begin{array}{l}\text { RSD } \\
(\%, n=3)\end{array}$ \\
\hline 1 & 0.10 & 0.12 & 107.2 & 2.5 \\
2 & 0.40 & 0.39 & 94.0 & 3.6 \\
3 & 1.00 & 0.98 & 96.6 & 2.1 \\
4 & 1.50 & 1.60 & 103.3 & 3.3 \\
\hline
\end{tabular}

concentrations was added into the obtained water samples and then analyzed. The recovery results were listed in Table 1 . The recoveries of $\mathrm{Cu}^{2+}$ detection in real water samples are between 94.0 and $107.2 \%$, with a relative standard deviation (RSD) lower than $5 \%$. In addition, $\mathrm{Cu}^{2+}$-spiked river water samples 1 and 3 were also tested using ICP-MS. The concentrations of $\mathrm{Cu}^{2+}$ in these two samples were 0.114 and $1.01 \mu \mathrm{M}$, which is close to the results obtained by the proposed methods. The above results demonstrate that our method has potential for application to monitor $\mathrm{Cu}^{2+}$ in environment-related field.

\section{Conclusions}

In summary, a novel FP method for sensitive detection of $\mathrm{Cu}^{2+}$ was established based on the chemical ligation of DNA by click chemistry and signal amplification by silica nanoparticles. This method has several important features. First, the combination of FP and signal amplification by silica nanoparticles greatly improves the sensitivity of the method, achieving a detection limit of $0.0178 \mu \mathrm{M}$ for $\mathrm{Cu}^{2+}$. Secondly, the high specificity of the CuAAC reaction improves the reliability. In addition, the homogeneous FP assay does not need separation, washing, and other complex processes. Moreover, the proposed method also has a good analysis performance in river water samples. Consequently, the proposed FP-based $\mathrm{Cu}^{2+}$ detection method may hold the potential applications in environmental fields.

\section{Conflicts of interest}

There are no conflicts to declare.

\section{Acknowledgements}

This work was supported by the National Natural Science Foundation of China (No. 21645003).

\section{Notes and references}

1 (a) B. E. Kim, T. Nevitt and D. J. Thiele, Nat. Chem. Biol., 2008, 4, 176; (b) A. K. Boal and A. C. Rosenzweig, Chem. Rev., 2009, 109, 4760.

2 M. Bonham, J. M. O'Connor, B. M. Hannigan and J. J. Strain, Br. J. Nutr., 2002, 87, 393-403.

3 (a) P. G. Georgopoulos, A. Roy, M. J. Yonone-Lioy, R. E. Opiekun and P. J. Lioy, J. Toxicol. Environ. Health, Part B, 2001, 4, 341-394; (b) B. P. Zietz, H. H. Dieter, 
M. Lakomek, H. Schneider, B. K. Gaedtke and H. Dunkelberg, Sci. Total Environ., 2003, 302, 127-144.

4 J. Chen and K. C. Teo, Anal. Chim. Acta, 2001, 450, 215-222. 5 A. Milne, W. Landing, M. Bizimis and P. Morton, Anal. Chim. Acta, 2010, 665, 200-207.

6 L. M. Zhang, Y. Y. Han, F. Zhao, G. Y. Shi and Y. Tian, Anal. Chem., 2015, 87, 2931-2936.

7 V. Tharmaraj and J. Yang, Analyst, 2014, 139, 6304-6309.

8 (a) X. J. Liu, N. Zhang, T. Bing and D. H. Shangguan, Anal. Chem., 2014, 86, 2289; (b) Y. Su, B. Shi, S. Liao, Y. Qin, L. Zhang, M. Huang and S. Zhao, Sens. Actuators, B, 2016, 225, 334.

9 (a) V. V. Rostovtsev, L. G. Green, V. V. Fokin and K. B. Sharpless, Angew. Chem., 2002, 114, 2708; (b) Q. Wang, T. R. Chan, R. Hilgraf, V. V. Fokin, K. B. Sharpless and M. G. Finn, J. Am. Chem. Soc., 2003, 125, 3192.

10 V. P. Mocharla, B. Colasson, L. V. Lee, S. Roper, K. B. Sharpless, C. Wong and H. C. Kolb, Angew. Chem., Int. Ed., 2005, 44, 116.

11 M. J. Joralemon, R. K. O'Reilly, C. J. Hawker and K. L. Wooley, J. Am. Chem. Soc., 2005, 127, 16892.

12 K. E. Beatty, F. Xie, Q. Wang and D. A. Tirrell, J. Am. Chem. Soc., 2005, 127, 14150.
13 X. Xu, W. L. Daniel, W. Wei and C. A. Mirkin, Small, 2010, 6, 623.

14 Q. P. Shen, L. F. Zhou, Y. J. Yuan, Y. Huang, B. B. Xiang, C. Y. Chen, Z. Nie and S. Z. Yao, Biosens. Bioelectron., 2014, $55,187$.

15 J. A. Cruz-Aguado and G. Penner, Anal. Chem., 2008, 80, 8853. 16 D. M. Jameson and J. A. Ross, Chem. Rev., 2010, 110, 2685.

17 J. Zhao, Z. Chu, X. Jin and S. Zhao, Sens. Actuators, B, 2015, 209, 116.

18 Y. Huang, M. Shi, L. M. Zhao, S. L. Zhao, K. Hu, Z. F. Chen, J. Chen and H. Liang, Biosens. Bioelectron., 2014, 54, 285.

19 Y. C. He, B. C. Yin, L. H. Jiang and B. C. Ye, Chem. Commun., 2014, 50, 6236.

20 Y. Huang, J. Chen, M. Shi, S. L. Zhao, Z. F. Chen and H. Liang, J. Mater. Chem. B, 2013, 1, 2018.

21 Q. Shen, W. Li, S. Tang, Y. Hu, Z. Nie, Y. Huang and S. Yao, Biosens. Bioelectron., 2013, 41, 663.

22 C. C. Ge, Q. Luo, D. Wang, S. M. Zhao, X. L. Liang, L. X. Yu, X. R. Xing and L. W. Zeng, Anal. Chem., 2014, 86, 6387.

23 T. Sanji, M. Nakamura and M. Tanaka, Tetrahedron Lett., 2011, 52, 3283.

24 J. Su, J. Xu, Y. Chen, Y. Xiang, R. Yuan and Y. Chai, Biosens. Bioelectron., 2013, 45, 219. 